\title{
Allocation of time in reading aloud: Being fluent is not the same as being rhetorical
}

\author{
DANIEL C. O'CONNELL \\ Loyola University of Chicago, Chicago, Illinois \\ and Georgetown University, Washington, D.C. \\ SABINE KOWAL, UTE BARTELS, and HEINRICH MUNDT \\ Technical University of Berlin, Berlin, West Germany \\ and \\ DONNA A. VAN DE WATER \\ Loyola University of Chicago, Chicago, Illinois
}

\begin{abstract}
A total of 24 subjects in four groups (German and American women and men) read aloud two passages from political speeches in their native language. Compared with the politicians' (Helmut Kohl, Willy Brandt, and Ronald Reagan) readings and readings by a German and an American actor, subjects used less reading time. Their articulation rates were faster, and their pauses were shorter and less numerous. Punctuation was predictive of both pause allocation and pause duration. Commas were predictive of pause allocation differentially in German and English. The inability of otherwise fluent adults to use reading time for simulated persuasion is discussed.
\end{abstract}

Two recent studies (Kowal, 1988; O’Connell, 1988) reviewed the research literature on the allocation of time in reading aloud. In general, it has been found that fluent adults reading aloud in their native language under experimental conditions use less time for pausing and articulate more rapidly than do readers whose intention is expressive or persuasive. In particular, Kowal's own data indicated that the politicians in her study consistently read more slowly than experimental subjects in the archival literature who did experimental readings aloud without any rhetorical intention to be expressive or to persuade, and, of course, without a real audience.

Even when instructed to read expressively, experimental subjects do not change the temporal organization of their reading (see, e.g., Clemmer, O'Connell, \& Loui, 1979; O'Connell \& Kowal, 1984). The texts used in such research have been quite dramatic; for example, Clemmer et al. used a passage from St. Paul, and O'Connell and Kowal used German and American poetry. The demands of such expressiveness seem to be beyond the ability of ordinary adult subjects in comparison with the abilities of actors and poets.

Such direct comparisons between experts on the one hand and ordinary fluent adults on the other have not as yet been made with rhetorical texts intended originally for the purpose of persuasion. Political texts provide appropriate material for such comparisons. The original readings on the part of the politicians themselves provide the expert productions. In addition to ordinary fluent

Address correspondence to Daniel C. O'Connell, Department of Psychology, Loyola University of Chicago, 6525 Sheridan Road, Chicago, IL 60626. adults, however, another type of reader is of interest by way of comparison-the dramatic actor. By training, the actor is a specialist in the rhetoric of expression, but not necessarily in the rhetoric of persuasion. Kowal's (1988) comparisons of the archival literature have indicated correspondingly that, in general, expression requires more time than persuasion.

Our generic hypothesis, then, is that actors, in keeping with their dramatic training and experience, would use the most time in reading a political text aloud. The politicians would take less time, because their purpose is not to be dramatically expressive, but to persuade their audience regarding political issues. The ordinary fluent adult subject was expected to use the least time of all. His/her training and experience in reading aloud are generally severely limited. Both the actors and the experimental subjects differ from the politicians, however, in that neither group reads for an actual audience and neither reads their own texts. These characteristics, in fact, identify the readings of both actors and experimental subjects as not persuasive. The question then arises whether these readers can simulate persuasiveness under these limiting conditions. If they influence the time allocation of the actors, the generic hypothesis stated above would be counterindicated; the actors would not be expected to use more time than the politicians in their readings.

Of course, an entirely different prediction is possible, and it is far more in keeping with the traditional archival literature than any of the above speculations. In general, the prediction states that temporal organization in reading is determined mainly by syntactic structure. Brown and Miron (1971), for example, claimed that "fluent oral readers tend to pause at grammatical junctures" and that 
"pause durational values in oral reading actively reflect an 'understanding' of sentence structure"' (p. 665). Butcher (1981), Goldman-Eisler (1972), and Grosjean and Collins (1979) are essentially in agreement regarding the syntactic determination of temporal organization.

In the present study, the syntactic structure of specific political texts, to be read by actors and adult experimental subjects and compared with the original readings by politicians, remains constant across these groups. In other words, syntactic determination of temporal organization would predict no differences among the three groups.

The prediction of syntactic determination of temporal organization has been approached from quite another point of view by both O'Connell and Kowal (1986) and Van De Water and O'Connell (1986). Their evidence indicated that the temporal organization of reading aloud can be predicted more parsimoniously from an analysis of punctuation than from an analysis of syntactic structure.

In the present study, punctuation is identical for actors, politicians, and experimental subjects. In keeping with our 1986 research (O'Connell \& Kowal, 1986; Van De Water \& O'Connell, 1986), therefore, we would expect to find commonalities across the three groups with respect to punctuation types: The longest pauses would occur at period (P) positions, pauses of intermediate duration at comma (C) positions, and the shortest pauses in unpunctuated (U) positions. In terms of the proportion of available positions used for pausing, a similar sequence of magnitudes is to be expected. In other words, for both response measures, pause duration and proportion of positions used, the hypothesis can be expressed as follows: $\mathrm{P}>\mathrm{C}>\mathrm{U}$.

\section{METHOD}

To implement the experimental rationale described above, we selected four segments of political speeches originally presented on television by two German politicians (Helmut Kohl and Willy Brandt) and by
Ronald Reagan (Segments A and B). The respective lengths (in syllables) and total reading times (in seconds) of these segments were as follows: $173,51.02 ; 170,41.02 ; 128,34.70$; and 185, 45.80. The German segments were both from 1983 political campaigns; the segments by Reagan were both taken from his first televised speech from the Oval Office in January 1981. One German and one American professional actor read the segments in their native language with the same instructions and in the same setting as did the experimental subjects.

Six men and 6 women university students were instructed to read aloud the two segments in their native languages (German and English). Hence, the total number of subjects was 24 . Instructions were to read the segments as the reader thought appropriate to the content, genre, and purpose of the political communication. Sequence of the two segments was counterbalanced across subjects.

For the four segments, cassette recordings of media quality were derived from the television programs. These recordings were then subjected to temporal analysis by means of a Siemens Oscillomink $\mathrm{L}$ and F-J fundamental frequency meter (Type FFM 6502), with a minimum pause cutoff point of $0.13 \mathrm{sec}$. Since printed transcriptions of the segments were not available, punctuation and other typographical details were determined by the present authors.

Transcriptions of each segment, typed in paragraph format, were presented to subjects individually. They were encouraged to study the paragraph to determine how they wished to read it and to let the experimenter know when they were ready to have their reading recorded.

\section{RESULTS}

Audiocassette recordings of actors' and subjects' readings were analyzed by means of the same equipment used for the original readings. The response measures tabulated from these level recordings were the following: articulation rate (syllables/sec of on time), percentage of pause time/total time, pause duration (in seconds), and phrase length (syllables/pause). In addition, pauses at three specific positions (periods, commas, and unpunctuated positions) were segregated for further analysis. In the present corpus, no other punctuation types occurred.

Group means and standard deviations of the four response measures are presented in Table 1 for all read-

Table 1

Response Measures and Group Means (Ms) and Standard Deviations (SDs) for Political Readings in German and English by Politicians, Actors, and Subjects

\begin{tabular}{|c|c|c|c|c|c|c|c|}
\hline \multirow[b]{2}{*}{ Language } & \multirow[b]{2}{*}{ Segment } & \multirow[b]{2}{*}{ Reader } & & \multicolumn{4}{|c|}{ Response Measures } \\
\hline & & & & $\mathrm{AR}$ & $\%$ & PD & PL \\
\hline \multirow[t]{8}{*}{ German } & Kohl & H. Kohl & & 4.78 & 29 & 0.68 & 7.5 \\
\hline & & Actor & & 4.86 & 33 & 0.76 & 7.2 \\
\hline & & Subjects & $M$ & 5.64 & 18 & 0.52 & 13.0 \\
\hline & & & $S D$ & 0.41 & 4 & 0.12 & 2.5 \\
\hline & Brandt & W. Brandt & & 4.83 & 14 & 0.39 & 10.6 \\
\hline & & Actor & & 4.88 & 27 & 0.85 & 10.7 \\
\hline & & Subjects & $M$ & 5.84 & 17 & 0.52 & 13.9 \\
\hline & & & $S D$ & 0.45 & 3 & 0.11 & 3.2 \\
\hline \multirow[t]{8}{*}{ English } & Reagan A & R. Reagan & & 4.71 & 22 & 0.68 & 10.7 \\
\hline & & Actor & & 4.64 & 26 & 0.84 & 7.2 \\
\hline & & Subjects & $M$ & 5.46 & 17 & 0.52 & 13.0 \\
\hline & & & $S D$ & 0.44 & 4 & 0.12 & 2.3 \\
\hline & Reagan B & R. Reagan & & 5.43 & 26 & 0.65 & 9.7 \\
\hline & & Actor & & 5.32 & 20 & 0.58 & 11.6 \\
\hline & & Subjects & $M$ & 5.97 & 15 & 0.44 & 14.2 \\
\hline & & & $S D$ & 0.37 & 4 & 0.08 & 3.5 \\
\hline
\end{tabular}

Note $-\mathrm{AR}=$ articulation rate (in syllables $/ \mathrm{sec}$ ). $\%=$ percentage of pause time/total time. $\mathrm{PD}=$ pause duration (in sec). PL = phrase length (in syllables/pause). 
ings. For each segment, there is only one reading by a politician and one reading by an actor; hence, there are no group means in these cases.

Group means of the German and the American subjects were tested separately by means of $2 \times 2$ analyses of variance for all the response measures. Sex of subjects was a between-subjects variable, and segment (Kohl, Brandt; Reagan A, and Reagan B) a within-subjects variable. Sex of subjects proved significant only for the English data for one response measure, pause duration $[F(1,10)=$ $5.27, p<.05]$ : Men used longer pauses $(0.53 \mathrm{sec}, S D=$ $0.12)$ than women $(0.42 \mathrm{sec}, S D=0.03)$. In the case of both German and English segments, articulation rate was significant $[F(1,10)=11.0, p<.01 ; F=88.26$, $p<.005$, respectively]. The English segments were also significantly different from one another in pause duration $[F(1,10)=22.5, p<.005]$ and percentage of pause time/total time $[F(1,10)=6.0, p<.05$.

With regard to articulation rate, it is clear that each segment was articulated similarly by the politician and the actor. Subjects, on the other hand, articulated consistently more rapidly. Only one experimental subject exhibited an articulation rate (for both Reagan segments) that overlapped with any of the articulation rates of actors or politicians. In view of these differences, inferential statistics would appear redundant.

With regard to percentage of pause time/total time, the most striking result is that Brandt had a smaller percentage than all others, with the exception of one experimental subject. Otherwise, both actors and politicians consistently used $\geq 20 \%$ pause time. The mean percentages of experimental subjects are far less than this figure, but the individual percentages of 4 subjects are nonetheless $>20 \%$.

Pause duration presents a far more complex picture. The generic hypothesis that actors would use the longest pauses, politicians intermediate pause durations, and subjects the shortest pauses is not confirmed. Brandt and the American actor in his reading of the Reagan B segment exhibited shorter pause duration than predicted. Otherwise, there was remarkable agreement among politicians and among actors. The subjects' mean durations are ex-

Table 2

Percentages of Period (P), Comma (C), and Unpunctuated (U) Positions Used by Politicians, Actors, and Subjects for Pausing

\begin{tabular}{|c|c|c|c|c|c|}
\hline \multirow[b]{2}{*}{ Language } & \multirow[b]{2}{*}{ Segment } & \multirow[b]{2}{*}{ Reader } & \multicolumn{3}{|c|}{ Position } \\
\hline & & & $\mathbf{P}$ & $\mathrm{C}$ & $\mathbf{U}$ \\
\hline \multirow[t]{6}{*}{ German } & Kohl & H. Kohl & 100 & 67 & 16 \\
\hline & & Actor & 100 & 67 & 16 \\
\hline & & Subjects & 98 & 79 & 4 \\
\hline & Brandt & W. Brandt & 100 & 43 & 8 \\
\hline & & Actor & 100 & 57 & 7 \\
\hline & & Subjects & 98 & 62 & \\
\hline \multirow[t]{6}{*}{ English } & Reagan A & R. Reagan & 100 & 100 & 14 \\
\hline & & Actor & 100 & 100 & 14 \\
\hline & & Subjects & 100 & 83 & \\
\hline & Reagan B & R. Reagan & 100 & 100 & \\
\hline & & Actor & 100 & 100 & \\
\hline & & Subjects & 100 & 86 & 3 \\
\hline
\end{tabular}

Table 3

Response Measures and Group Means (Ms) and Standard Deviations (SDs) of Pause Duration (in sec) in Period (P), Comma (C), and Unpunctuated (U) Positions for Politicians, Actors, and Subjects

\begin{tabular}{|c|c|c|c|c|c|c|}
\hline \multirow[b]{2}{*}{ Language } & \multirow[b]{2}{*}{ Segment } & \multirow[b]{2}{*}{ Reader } & & \multicolumn{3}{|c|}{ Position } \\
\hline & & & & $\mathbf{P}$ & $\mathrm{C}$ & $\mathrm{U}$ \\
\hline \multirow[t]{8}{*}{ German } & Kohl & H. Kohl & & 0.98 & 0.78 & 0.52 \\
\hline & & Actor & & 1.32 & 0.75 & 0.56 \\
\hline & & Subjects & $M$ & 0.72 & 0.45 & 0.36 \\
\hline & & & $S D$ & 0.26 & 0.16 & 0.08 \\
\hline & Brandt & W. Brandt & & 0.59 & 0.39 & 0.25 \\
\hline & & Actor & & 1.36 & 0.66 & 0.56 \\
\hline & & Subjects & $M$ & 0.74 & 0.39 & 0.35 \\
\hline & & & $S D$ & 0.18 & 0.09 & 0.16 \\
\hline \multirow[t]{8}{*}{ English } & Reagan A & R. Reagan & & 0.90 & 0.58 & 0.42 \\
\hline & & Actor & & 1.19 & 0.39 & 0.33 \\
\hline & & Subjects & $M$ & 0.67 & 0.39 & 0.25 \\
\hline & & & $S D$ & 0.20 & 0.07 & 0.12 \\
\hline & Reagan B & R. Reagan & & 1.07 & 0.59 & 0.49 \\
\hline & & Actor & & 0.89 & 0.51 & 0.41 \\
\hline & & Subjects & $M$ & 0.71 & 0.34 & 0.25 \\
\hline & & & $S D$ & 0.22 & 0.09 & 0.09 \\
\hline
\end{tabular}

actly the same for three of the four segments, and the corresponding standard deviations are all quite small.

The predicted use of more time on the part of both politicians and actors (relative to experimental subjects) logically entails the use of shorter phrases. The corresponding prediction-namely that politicians and actors would exhibit shorter phrase length than the experimental subjects-is reflected in the data presented in Table 1 . Nonetheless, 2 individual subjects' means were smaller than both the corresponding actor's and politician's phrase length.

Table 2 presents percentages of $\mathrm{P}, \mathrm{C}$, and $\mathrm{U}$ positions used by politicians, actors, and subjects for pausing. Our hypothesis that $\mathrm{P}>\mathrm{C}>\mathrm{U}$ was confirmed. Virtually all period positions were used by politicians, actors, and subjects for pausing. The intermediate proportions of comma positions used for pausing are quite different for German and English; all the German entries in Table 2 are smaller than any of the English entries. This finding may be in part traceable to the fact that subordinate clauses are mandatorily marked by commas in German, whereas use of commas in English is far more optional and therefore variable. In the present corpus, punctuation spans (syllables/comma) in the German segments are smaller than punctuation spans in the English segments: for Kohl, Brandt, Reagan A, and Reagan B, respectively, span is $28.8,24.3,43.0$, and 30.8. German subjects consistently used a larger proportion of comma positions for pausing, whereas English subjects used a smaller proportion than the corresponding politician and actor. Finally, the unpunctuated positions exhibit the smallest proportion of pauses. Subjects consistently used a smaller proportion of these positions for pausing than did any of the politicians and actors. In all the entries of Table 2, politicians and actors are identical except Brandt.

In Table 3, pause durations at the three punctuation positions are presented for politicians, actors, and subjects. The general hypothesis, $\mathrm{P}>\mathrm{C}>\mathrm{U}$, is clearly confirmed 
in every row of the table. It is noteworthy that these relative durations are the case both when the mean duration of pauses for a given individual or group is long and when it is short. The longest and the shortest pause durations listed in Table 1, for example, are 0.85 and $0.39 \mathrm{sec}$. The corresponding $\mathrm{P}, \mathrm{C}$, $\mathrm{U}$ sets of durations even in these two extreme cases are $1.36,0.66,0.56 \mathrm{sec}$, and $0.59,0.39$, $0.25 \mathrm{sec}$.

It is also evident from Table 3 that the actors (Reagan included) used period positions for unusually long pauses. The relative durations of pauses of the other politicians and the subjects at these positions were considerably shorter for each segment. Hence, the simulation of persuasion on the part of the actors can be said to involve a certain rhetorical or dramatic exaggeration.

\section{DISCUSSION}

As would be expected for experimental reading, the subjects in the present experiment articulated rather rapidly and used a small percentage of their time in pausing. Their overall articulation rate of 5.73 syllables/sec is in close agreement with the articulation rate of Butcher's (1981) subjects, who read narrative prose at 5.55 syllables $/ \mathrm{sec}$. Similarly, the present subjects used $16.6 \%$ of their time for pausing, compared with $21.3 \%$ for Butcher's subjects. Our subjects, therefore, could hardly be said to have used any additional on time or off time to simulate the persuasive purpose of the political text. There is no evidence in our data that they read differently in any way as a consequence of our instructions.

The politicians and actors, on the other hand, articulated more slowly and, with the exception of Brandt, used a greater percentage of their time in pausing. The remaining two response measures, pause duration and phrase length, did not clearly distinguish readings of the politicians and actors from readings of the subjects.

We had predicted that the actors would, by reason of their training and experience in dramatic expressiveness, take more time than the politicians, that is, that they would articulate more slowly and use a greater percentage of their time for pausing. Such was clearly not the case. One could argue, of coutse, that Reagan is both politician and actor. Even in his case, however, the situation was not the same as that of the actors; Reagan was genuinely engaged in persuading a real audience, and the material he read was his own. This was not the case with the actors. If they read very much as the politicians did, it must still be looked upon as a type of simulation rather than actual persuasion. They seem to have done a good job of simulating, at least as regards temporal organization, but the lack of a real audience to be persuaded seems to have muted their rhetoric.

Our data are dramatically in accord with those of O'Connell and Kowal (1986) and Van De Water and O'Connell (1986) with respect to the prediction of pauses according to punctuation position. The $\mathrm{P}>\mathrm{C}>\mathrm{U}$ sequence for both response measures, pause duration and proportion of available positions used for pausing, indicates that punctuation provides a more parsimonious explanation of the orderliness of pausing behavior than does syntax. It proves quite feasible for subjects to use the obvious cues of punctuation instead of being expected to undertake complex analyses of syntax in order to pause efficiently.

Within-phrase pauses (see Kowal, 1988, p. 238) made up a subset of the pauses at $U$ positions. Reagan used no within-phrase pauses; the other actors and politicians used some rhetorically, but none in conjunction with reading errors; the subjects used 59\% (19/32) of their within-phrase pauses in conjunction with corrected reading errors. Of the total number of pauses used by politicians, actors, and subjects, respectively, within-phrase pauses not associated with reading errors were $3.0 \%, 12.8 \%$, and $1.6 \%$. It is certainly paradoxical that the other actors used these within-phrase pauses most dramatically, whereas Reagan did not use them at all.

The fact that use of commas is mandatory in German in many positions in which their use is quite optional in English provides the only difference traceable to native language in the present experiment. In general, the similarities between the German and English reading data in this experiment are quite remarkable.

Were Brandt the only German politician whose reading was analyzed in the present experiment, we might have assumed that German and American politicians do differ because of native language. Or we might have assumed that Reagan differed because of his acting experience. However, it was Brandt's use of off time, not Reagan's, that was quite unlike that of the other politicians and the actors, and more like that of the subjects. Fortunately, Kohl's reading was also analyzed. The differences between Kohl's and Brandt's readings make clear the importance of stylistic variations idiosyncratic to a given reader, a phenomenon that has been noted by Duez (1982) in her analyses of French politicians' readings and by Kowal (1988), but has been otherwise seriously neglected in psycholinguistic research. Kohl's readings are quite similar to Reagan's English readings and to the actors' readings. This similarity of German and English with respect to the temporal organization of readings is also in keeping with the findings of Kowal (1988).

The differences noted between the Reagan A and Reagan B segments pinpoint the importance of the text itself. Reagan himself, the actor, and the subjects all articulated more slowly in reading Reagan A than in reading Reagan B. It should be recalled that both segments were excerpted from the same speech.

Neither punctuation nor syntax would account for the differences in pausing across politicians, actors, and subjects in the present experiment; both punctuation and syntax remained constant in all these subject conditions. The differences found between politicians and actors on the one hand and subjects on the other must be explained in terms of experience and training, that is, in terms of rhetorical skills in the use of language.

The experimental subjects in the present experiment were normally skilled adult readers of their native language. They were fluent in their readings, but not eloquent. It appears to be quite clear that normal adult readers are simply not capable of reading with the same rhetorical eloquence that politicians and actors alike are able to bring to a persuasive task. The politicians attempt to persuade; the actors attempt to simulate persuasion; the fluent adults do neither. As we stated in our title, the allocation of time in reading aloud indicates that being fluent is not the same as being rhetorical. Eloquence is a concretely identifiable learned skill.

\section{REFERENCES}

Brown, E., \& Miron, M. S. (1971). Lexical and syntactic predictors of the distribution of pause time in reading. Journal of Verbal Learning \& Verbal Behavior, 10, 658-667.

Butcher, A. (1981). Aspects of the speech pause: Phonemic correlates and communicative functions. Kiel, West Germany: Universität Kiel, Institut für Phonetik.

Clemmer, E. J., O’Connell, D. C., \& Loui, W. (1979). Rhetorical pauses in oral reading. Language \& Speech, 22, 397-405.

DuEz, D. (1982). Silent and non-silent pauses in three speech styles. Language \& Speech, 25, 11-28.

Goldman-EIsLER, F. (1972). Pauses, clauses, sentences. Language \& Speech, 15, 103-113.

Grosjean, F., \& Collins, M. (1979). Breathing, pausing, and reading. Phonetica, 36, 98-114.

Kowal, S. (1988). Die allmähliche Verfertigung der Gedanken beim Reden. Eine sprachpsychologische Untersuchung zum Gebrauch von Zeit in politischer Rede. Habilitationsschrift, Technische Universität, Berlin.

O'ConNell, D. C. (1988). Critical essays on language use and psychology. New York: Springer-Verlag.

O'ConNell, D. C., \& Kowal, S. (1984). Comparisons of native and foreign language poetry readings: Fluency, expressiveness, and their evaluation. Psychological Research, 46, 301-313.

O'CONNELL, D. C. , \& KowAL, S. (1986). Use of punctuation for pausing: Oral readings by German radio homilists. Psychological Research, 48, 93-98.

Van De Water, D. A., \& O'Connell, D. C. (1986). From page to program: Some typographical and temporal variables in radio homilies. Journal of Psycholinguistic Research, 15, 525-538.

(Manuscript received September 15, 1988.) 